\title{
The correlation between red cell distribution width, autoimmunity and nail involvement in alopecia areata
}

\author{
Gülhan Gürel॰
}

Department of Dermatology, Bozok University School of Medicine, Yozgat, Turkey

DOI: $10.18621 /$ eurj.408089

\begin{abstract}
Objectives: Alopecia areata is a widespread autoimmune disease that targets hair follicles, and is characterized by nonscarring patches of hair loss. Red cell distribution width (RDW) is a routinely analyzed parameter during complete blood count, and indicates variations in diameters of red blood cells. Elevated RDW levels are associated with high level of inflammation and oxidative stress. In this study, we aimed to demonstrate the correlation between RDW levels, autoimmunity, and nail involvement in alopecia areata.

Methods: Medical records of 170 patients who were admitted to our dermatology clinic between May 2016 and May 2017 were retrospectively evaluated. A total of 170 patients with alopecia areata diagnosis were evaluated.

Results: The mean age of the patients was $24.61 \pm 12.62$ years (3-59 years). Sixty patients (35.3\%) were female, and 110 patients $(64.7 \%)$ were male. Twenty-seven patients $(15.9 \%)$ had nail involvement, and 24 patients $(14.1 \%)$ had a history of an autoimmune disease. RDW levels were significantly higher in patients with nail involvement and history of an autoimmune disease.

Conclusion: RDW can be used as a simple, cheap, and readily available marker of inflammation in patients with alopecia areata.
\end{abstract}

Keywords: Alopecia areata, red cell distribution width, autoimmunity

Received: March 20, 2018; Accepted: November 22, 2018; Published Online: November 23, 2018

A lopecia areata (AA) is a common autoimmune disease that targets hair follicles, and is characterized by nonscarring patches of hair loss [1]. AA affects only $0.1-0.2 \%$ of the general population, and can be seen in both genders and at all ages [2]. The exact cause of AA is not known; still, AA is considered as an autoimmune disease resulting from damage to hair follicles by $\mathrm{T}$ lymphocytes. The disease with localized hair loss is manifested by severe lymphocytic infiltration around the hair follicle [3, 4]. Genetic background, atopy, nonspecific immune reactions, organ-specific autoimmune reactions, emotional stress factors, infections, and neuropeptides are considered to play a role in disease etiology [5]. Red cell distribution width (RDW) is a routinely reported parameter in complete blood count, and represents the variation in diameters of red blood cells (RBCs) [6]. In addition to RDW, mean platelet volume (MPV) is also considered as a marker of inflammation, and indicates the average size of platelets in blood. Both parameters can be analyzed easily in a routine complete blood count [7]. RDW has been studied in several diseases, such

Address for correspondence: Gülhan Gürel, MD., Bozok University School of Medicine, Department of Dermatology, Yozgat, Turkey

E-mail: gulhanozturkgurel@hotmail.com, Tel: +90 354 2127060, Fax:+90 3542177150 
as heart failure, rheumatoid arthritis, inflammatory bowel disease, and psoriasis, and has been considered as a marker of inflammation $[8,9]$. Elevated RDW levels have been linked to levels of inflammation and oxidative stress in the body [10]. Here, we aimed to demonstrate the correlation between RDW levels, autoimmunity, and nail involvement in alopecia areata.

\section{METHODS}

Medical records of 170 patients, who were admitted to our dermatology clinic between May 2016 and May 2017, and who were diagnosed with AA, were retrospectively evaluated.Patients' age, gender, area of involvement (scalp, beard, eyebrows, mixed, universal), nail involvement (pitting, leukonychia, trachonychia, longitudinal striation) and history of anautoimmunedisease (thyroid diseases, vitiligo, psoriasis, ankylosing spondilitis) were recorded from medical files.Patients with active inflammation and infection were excluded from the study.Laboratory parameters, including hemoglobin level, neutrophil count, lymphocyte count, RDW, MPV, glucose, vitamin $\mathrm{B} 12$, thyroid stimulating hormone (TSH), free triiodothyronine (fT3), free thyroxine (fT4), thyroglobulin antibody (anti-TG), and thyroid peroxidase antibody (anti-TPO), were recorded retrospectively.

\section{Statistical Analysis}

SPSS v.18.0 software was used for statistical analysis. Descriptive statistics of continuous variables were expressed as median without normal distribution (minimum-maximum). Mann Whitney $U$ test was used to identify the differences in continuous variables between the groups. Student's t-test was used for comparisons.For all tests, $\mathrm{p}$ values $<0.05$ were considered as statistically significant.

\section{RESULTS}

A total of 170 patients with AA diagnosis were evaluated. The mean age of the patients was $24.61 \pm$ 12.62 years (3-59 years). Sixty patients (35.3\%) were female, and 110 patients $(64.7 \%)$ were male. Scalp involvement was identified in 112 patients $(65.9 \%)$, beard involvement was identified in 32 patients (18.8\%), eyebrow involvement was identified in 4 patients $(2.4 \%)$, mixed involvement was identified in 16 patients $(9.4 \%)$, and universal involvement was identified in 6 patients (3.5\%). Twenty-seven patients $(15.9 \%)$ had nail involvement (pitting, leukonychia,

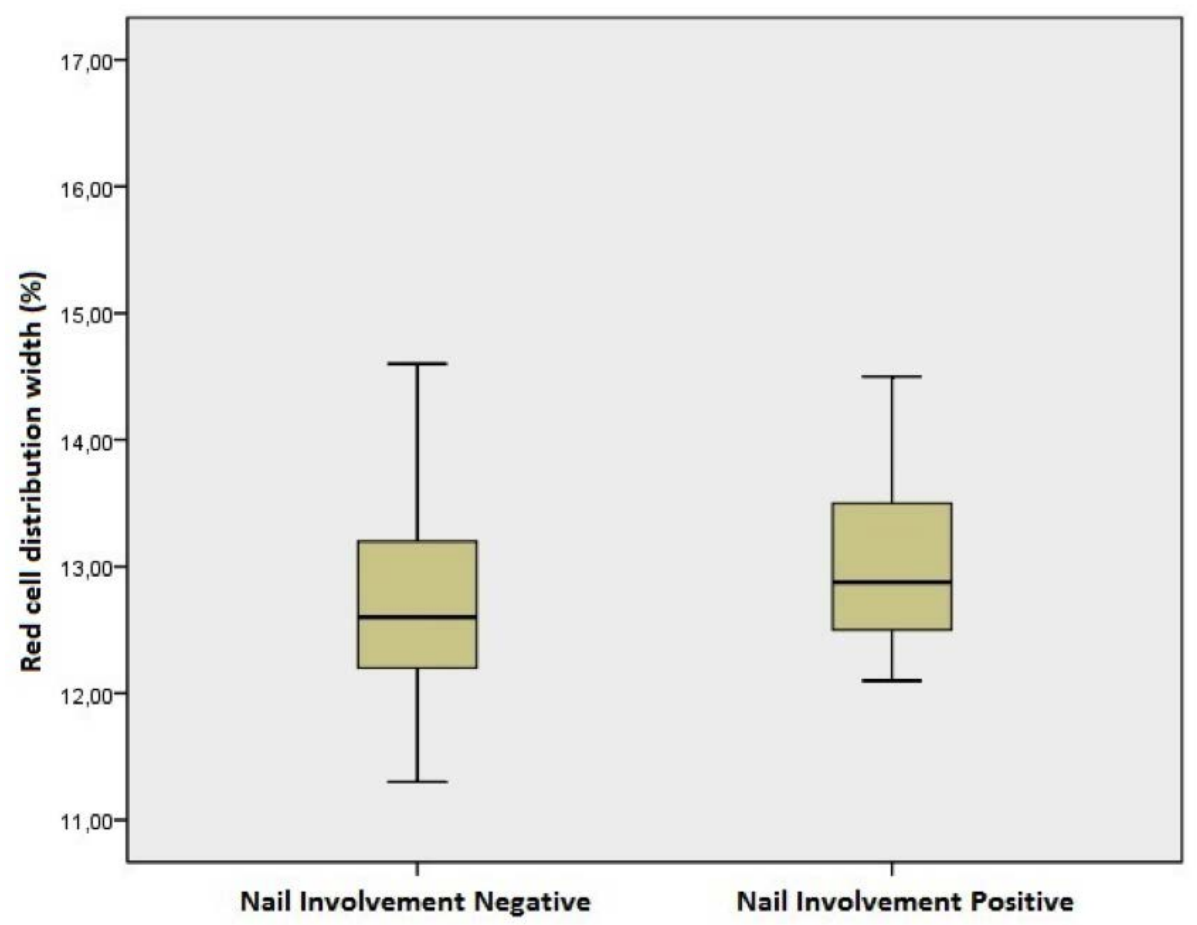

Figure 1. Relationship between RDW levels and nail involvement. 
trachonychia, longitudinal striation). Twenty-four patients $(14.1 \%)$ had a history of an autoimmune disease (most commonly thyroid diseases, vitiligo, psoriasis, and ankylosing spondylitis).

The mean age of patients without nail involvement was $25.84 \pm 12.48$ years, and the mean age of patients withnail involvementwas $18.11 \pm 11.51$ years $(p<$ 0.01 ). There was no significant difference with respect to gender between patients with nail involvement and patients without nail involvement. No significant differences were found in lymphocyte count, hemoglobin, MPV, glucose, vitamin B12, TSH, sT3, anti-TG, and anti-TPO levels between patients with nail involvement and patients without nail involvement $(p>0.05)$. On the other hand, the mean neutrophil count was $4.20 \pm 1.39$ in patients without nail involvement, and $4.91 \pm 2.16$ in patients with nail involvement $(p=0.02)$. The mean RDW level was $12.77 \pm 0.79$ in patients without nail involvement, and $13.24 \pm 1.13$ in patients with nail involvement $(p=$ 0.041) (Figure 1). The mean ST4 value was $1.00 \pm$ 0.09 in patients without nail involvement, and $1.11 \pm$ 0.18 in patients with nail involvement $(p<0.01)$. The correlation between nail involvementand laboratory findings is summarized in Table 1.
When we analyzed the correlation between having history of an autoimmune disease and gender, the mean age of patients with an history of autoimmune disease was $24.34 \pm 12.29$ years, while the mean age of patients without an autoimmune disease $26.25 \pm$ 14.66 years. There was no significant difference with respect to age in both groups. Moreover, there was also no significant difference with respect to gender between patients with an history of autoimmune disease and patients without an history of an autoimmune disease. There were no significant differences in hemoglobin level, neutrophil count, leukocyte count, MPV, glucose, vitamin B12, TSH, and sT3 levels with respect to presence of an autoimmune disease $(p>0.05)$. A significant difference in the mean RDW level was found between patients without an autoimmune disease and patients with an autoimmune disease $(12.75 \pm 0.75$ vs $13.37 \pm$ $1.25 ; p=0.021$ ) (Figure 2). The mean ST4 level was $1.00 \pm 0.09$ in patients without an autoimmune disease, and $1.10 \pm 0.19$ in patients with an autoimmune disease $(p<0.01)$. The mean anti-TG level was $8.78 \pm 64.58$ in patients without an autoimmune disease, and $107.69 \pm 259.52$ in patients with an autoimmune disease $(p<0.01)$. The mean

Table 1. Comparison of nail involvement with demographic and laboratory parameters

\begin{tabular}{|c|c|c|c|}
\hline Parameters & $\begin{array}{l}\text { NI negative } \\
(n=143)\end{array}$ & $\begin{array}{l}\text { NI positive } \\
\quad(n=27)\end{array}$ & $p$ value \\
\hline Age (years) & $25.84 \pm 12.48$ & $18.11 \pm 11.51$ & $<0.01$ \\
\hline Sex (Male/Female) & $94 / 49$ & $16 / 11$ & 0.50 \\
\hline Hemoglobin(g/dL) & $14.95 \pm 1.51$ & $14.54 \pm 1.59$ & 0.20 \\
\hline Neutrophil $\left(10^{3} / \mu \mathrm{L}\right)$ & $4.20 \pm 1.39$ & $4.91 \pm 2.16$ & 0.02 \\
\hline Lymphocyte $\left(10^{3} / \mu \mathrm{L}\right)$ & $2.84 \pm 1.81$ & $3.15 \pm 2.48$ & 0.93 \\
\hline Red cell distribution width (\%) & $12.77 \pm 0.79$ & $13.24 \pm 1.13$ & 0.041 \\
\hline Mean corpuscular volüme (fL) & $10.32 \pm 1.09$ & $9.86 \pm 1.32$ & 0.057 \\
\hline Glucose $(\mathrm{mg} / \mathrm{dL})$ & $92.10 \pm 24.26$ & $87.74 \pm 9.84$ & 0.16 \\
\hline Vitamin B12 (pg/mL) & $338.80 \pm 185.27$ & $304.70 \pm 124.49$ & 0.88 \\
\hline $\begin{array}{l}\text { Thyroid stimulating hormone } \\
\text { (uIU/mL) }\end{array}$ & $1.88 \pm 1.04$ & $2.25 \pm 1.19$ & 0.13 \\
\hline Freetriiodothyronine $(\mathrm{pg} / \mathrm{mL})$ & $3.31 \pm 0.55$ & $3.41 \pm 0.65$ & 0.44 \\
\hline Freethyroxine (ng/dL) & $1.00 \pm 0.09$ & $1.11 \pm 0.18$ & $<0.01$ \\
\hline Thyroglobulin antibody (IU/mL) & $19.79 \pm 111.96$ & $38.43 \pm 147.75$ & 0.18 \\
\hline $\begin{array}{l}\text { Thyroid peroxidase antibody } \\
\text { (IU/mL) }\end{array}$ & $18.38 \pm 102.71$ & $176.41 \pm 355.17$ & 0.23 \\
\hline
\end{tabular}

Data are presented as mean \pm standard deviation. $\mathrm{NI}=$ nail involvement 


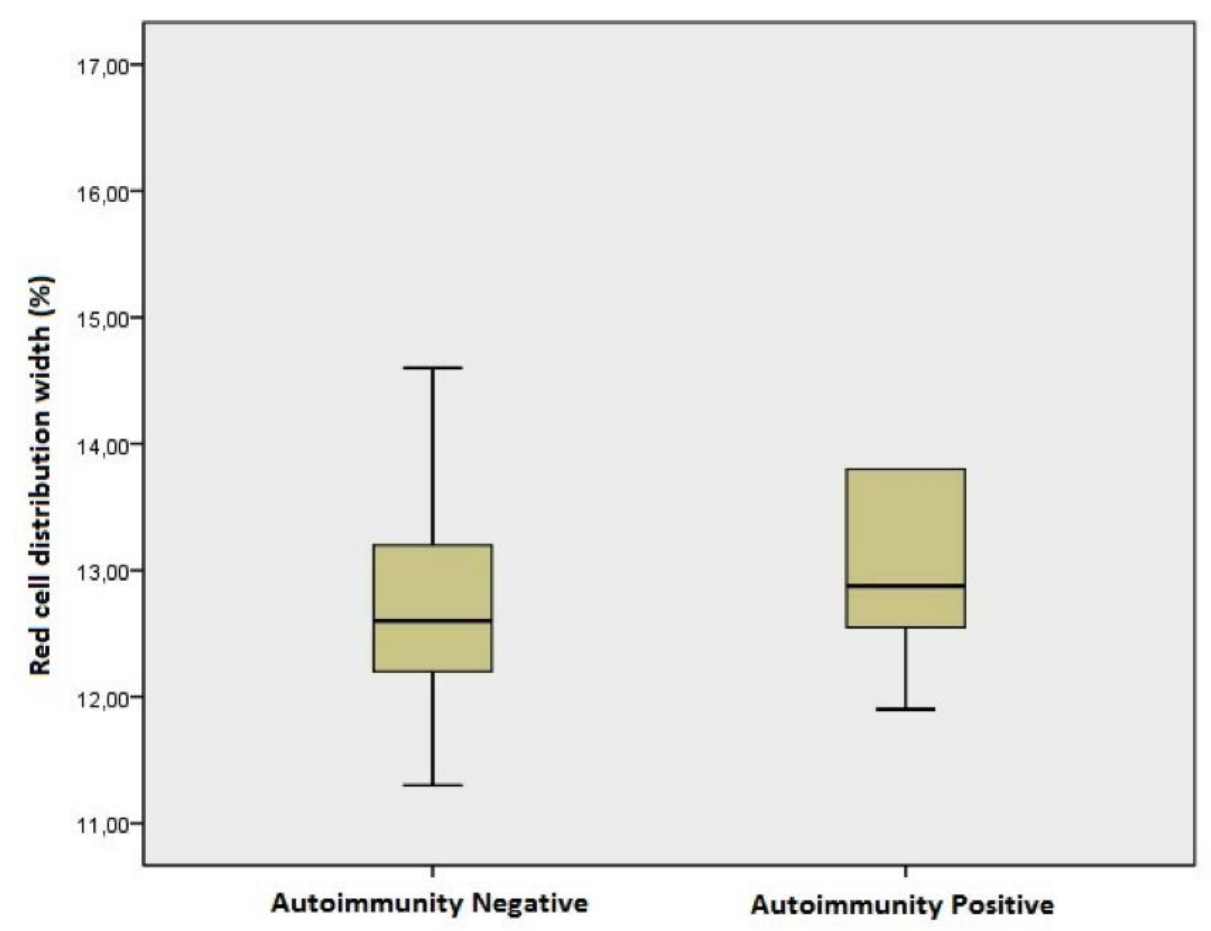

Figure 2. Relationship between RDW levels and autoimmunity.

anti-TPO value was $15.22 \pm 88.19$ in patients without an autoimmune disease, and $215.40 \pm 383.98$ in patients with an autoimmune disease $(p<0.01)$. The correlations between having a history of an autoimmune disease and laboratory findings is summarized in Table 2.

Overall, these results indicate that RDW levels are significantly higher in patients with nail involvement and a history of an autoimmune disease.

\section{DISCUSSION}

AA can be seen in both men and women. While some studies have reported an equal prevalence between women and men, others have reported that AA is more prevalent in women. Goh et al. [11] found the prevalence of AA in women and men to be $74.3 \%$ and $25.7 \%$, respectively. The study by Kavak et al. [12] showed that the prevalence of AA in females and

Table 2. Comparison of autoimmunitywithdemographicandlaboratoryparameters

\begin{tabular}{|c|c|c|c|}
\hline Parameters & $\begin{array}{l}\text { Autoimmunity negative } \\
\qquad(\mathrm{n}=146)\end{array}$ & $\begin{array}{l}\text { Autoimmunity positive } \\
\qquad(\mathrm{n}=24)\end{array}$ & $p$ value \\
\hline Age (years) & $24.34 \pm 12.29$ & $26.25 \pm 14.66$ & 0.49 \\
\hline Sex (Male/Female) & $94 / 52$ & $16 / 8$ & 0.83 \\
\hline $\operatorname{Hemog} \operatorname{lobin}(\mathrm{g} / \mathrm{dL})$ & $14.90 \pm 1.53$ & $14.76 \pm 1.48$ & 0.67 \\
\hline Neutrophil $\left(10^{3 / \mu \mathrm{L})}\right.$ & $4.23 \pm 1.42$ & $4.81 \pm 2.14$ & 0.09 \\
\hline Lymphocyte $\left(10^{3} / \mu \mathrm{L}\right)$ & $2.91 \pm 1.93$ & $2.77 \pm 1.94$ & 0.36 \\
\hline Red cell distribution width (\%) & $12.75 \pm 0.75$ & $13.37 \pm 1.25$ & 0.021 \\
\hline Mean corpuscular volüme (fL) & $10.31 \pm 1.02$ & $9.89 \pm 1.65$ & 0.09 \\
\hline Glucose $(\mathrm{mg} / \mathrm{dL})$ & $91.62 \pm 24.03$ & $90.13 \pm 10.88$ & 0.82 \\
\hline Vitamin B12 (pg/mL) & $337.56 \pm 182.04$ & $307.95 \pm 144.53$ & 0.65 \\
\hline Thyroid stimulating hormone (uIU/mL) & $1.89 \pm 1.01$ & $2.26 \pm 1.35$ & 0.11 \\
\hline Freetriiodothyronine $(\mathrm{pg} / \mathrm{mL})$ & $3.35 \pm 0.57$ & $3.22 \pm 0.59$ & 0.36 \\
\hline Freethyroxine (ng/dL) & $1.00 \pm 0.09$ & $1.10 \pm 0.19$ & $<0.01$ \\
\hline Thyroglobulinantibody (IU/mL) & $8.78 \pm 64.58$ & $107.69 \pm 259.52$ & $<0.01$ \\
\hline Thyroidperoxidaseantibody (IU/mL) & $15.22 \pm 88.19$ & $215.40 \pm 383.98$ & $<0.01$ \\
\hline
\end{tabular}

Data are presented as mean \pm standard deviation. 
males were $38.2 \%$ and $61.8 \%$, respectively. The prevalence of AA in the current study also showed a similar pattern; $35.3 \%$ of the patients were female, and $67.7 \%$ of the patients were male. While AA can be seen at almost all ages, it is reported to be more common in patients younger than 40 years, usually occurring in the first 3 decades of life [13]. Seyrafi et al. [14] found the mean age of AA patients to be 24.05 \pm 9.98 years. In the present study, the mean age of the patients was $24.61 \pm 12.62$ years, and this finding was consistent with the literature.

While AA affects all, most commonly affected regions are scalp, beard, and other regions [15]. Consistent with the literature, we identified scalp involvement in $65.9 \%$ of the patients, beard involvement in $18.8 \%$ of the patients, eyebrow involvement in $2.4 \%$ of the patients, mixed involvement in $9.4 \%$ of the patients, and universal involvement in $3.5 \%$ of the patients.

Nail involvement in AA is seen in 7-66\% of the cases, and it is reported that nail involvement is more common in cases of severe hair loss [16, 17]. Similarly, we identified nail involvement in $15.9 \%$ of the patients.

AA can be seen together with several organspecific autoimmune diseases. Thyroid diseases and vitiligo are the most common diseases which are seen together with AA [3]. It is reported that $5-17.5 \%$ of the patients with AA also have other autoimmune diseases [18]. Similarly, $14.1 \%$ of the patients in the current study had a history of an autoimmune disease (most commonly thyroid diseases).

RDW and MPV have been defined as markers of inflammation, and are used to predict prognosis of various diseases, includingcardiac diseases, inflammatory bowel diseases, psoriasis, rheumatoid arthritis, Behçet's disease, brucellosis, and vasculitis [19].To best of our knowledge, the correlation between nail involvement, history of autoimmune disease, and RDW in AA has not been investigated previously. This study shows that RDW levels are significantly high in patients with nail involvementand history of anautoimmune disease.

Inflammation is considered to play an important role in elevated RDW levels. Inflammatory cytokines (such as interferon- $\gamma$, TNF- $\alpha$, IL-1, IL-6, and IL-10) alters half-life of RBCs by causing changes in precursor cells and erythropoietin, thereby causing elevated RDW levels [20, 21].

Kim et al. [22] determined that patients with psoriasis have significantly higher RDW levels compared to healthy control subjects. At the same time, the authors revealed a correlation between RDW levels and disease severity; RDW levels were significantly higher in patients with moderate or severe psoriasis, compared to patients with mild psoriasis. Poor prognostic factors in AA include early disease onset, long disease duration, presence of alopecia totalis and alopecia universalis, nail involvement, comorbid atopical dermatitis, family history, and presence of other autoimmune disease [3]. Based on these studies, high RDW levels can be attributed to severe inflammation and poor prognosis in case of nail involvement and autoimmune disease in $\mathrm{AA}$.

Another study by Kim et al. [8] showed that patients with systemic vasculitis have higher RDW levels, compared to patients with localized cutaneous vasculitis. In addition, the authors identified RDW as an independent predictor of cutaneous vasculitis progression to systemic vasculitis.

Farkas et al. [23] demonstrated that RDW is a valuable parameter for multiple pathological processes (vasculopathy, fibrosis, and inflammation) in systemic sclerosis. In another study, Lou et al. [24] measured RDW levels in patients infected with hepatitis B virus, and determined a correlation between RDW levels and mortality. Based on these findings, RDW may serve as a valuable parameter to predict prognosis of AA.

\section{CONCLUSION}

Taken together, this study shows that RDW values are significantly high in patients with nail involvement and history of an autoimmune disease. RDW may serve as a simple, cheap, and easily accessible marker to indicate inflammation in patients with AA. Considering that the current study is a retrospective, single-center study, multi-center, prospective studies involving healthy control groups are required to validate these findings in AA.

\section{Conflict of interest}

The authors disclosed no conflict of interest during the preparation or publication of this manuscript. 


\section{Financing}

The authors disclosed that they did not receive any grant during conduction or writing of this study.

\section{REFERENCES}

[1] Alexis AF, Dudda-Subramanya R, Sinha AA. Alopecia areata: autoimmune basis of hair loss. Eur J Dermatol 2004;14:364-70.

[2] Kyriakis KP, Paltatzidou K, Kosma E, Sofouri E, Tadros A, Rachioti E. Alopecia areata prevalence by gender and age. J Eur Acad Dermatol Venereol 2009;23:572-3.

[3] Cotsarelis G, Botchkarev V. Biology of hair follicles. In:Wolff K, Katz SI, Goldsmith LA, Goldsmith L, Gilchrest B, Paller A, Leffell D, et al. Fitzpatrick's Dermatology in General Medicine. 7th ed. New York: Mc Graw Hill, 2007:pp. 39-9.

[4] Hordinsky MK. Alopecias. In:Horn, TD, Mascaro JM, Mancini AJ, et al. Dermatology. 1st ed. London: Mosby, 2003:pp. 1033-59.

[5] Wasserman D, Guzman-Sanchez DA, Scott K, McMichael A. Alopecia areata. Int J Dermatol 2007;46:121-31.

[6] Seçkin HY, Bütün I, Baş Y, Takcı Z, Kalkan G. Effects of colchicine treatment on mean platelet volume and the inflammatory markers in recurrent aphthous stomatitis. J Dermatolog Treat 2016;27:389-91.

[7] Schoorl M, Schoorl M, van Pelt J, Bartels PC. Application of innovative hemocytometric parameters and algorithms for improvement of microcytic anemia discrimination. Hematol Rep 2015;7:5843.

[8] Kim DS, Shin D, Kim TG, Kim SH, Kim DY, Kim SM, et al. Red blood cell distribution width as a useful indicator to predict systemic vasculitis in patients with cutaneous vasculitis. Rheumatol Int 2015;35:719-25.

[9] Felker GM, Allen LA, Pocock SJ, Shaw LK, McMurray JJ, Pfeffer MA, et al; CHARM Investigators. Red cell distribution width as a novel prognostic marker in heart failure: data from the CHARM Program and the Duke Databank. J Am Coll Cardiol 2007;50:40-7.

[10] Kurtul BE, Kabatas EU, Boybeyi SD, Caglar AA, Ozer PA. Increased red cell distribution width levels in children with seasonal allergic conjunctivitis. Int Ophthalmol 2018;38:107984.

[11] Goh C, Finkel M, Christos PJ, Sinha AA. Profile of 513 patients with alopecia areata: associations of disease subtypes with atopy, autoimmune disease and positive family history. J Eur Acad Dermatol Venereol 2006;20:1055-60.

[12] Kavak A, Yeşildal N, Parlak AH, Gökdemir G, Aydoğan I, Anul $\mathrm{H}$, et al. Alopecia areata in Turkey: demographic and clinical features. J Eur Acad Dermatol Venereol 2008;22:977-81. [13] Blaumeiser B, van der Goot I, Fimmers R, Hanneken S, Ritzmann S, Seymons K, et al. Familial aggregation of alopecia areata. J Am Acad Dermatol 2006;54:627-32.

[14] Seyrafi H, Akhiani M, Abbasi H, Mirpour S, Gholamrezanezhad A. Evaluation of the profile of alopecia areata and the prevalence of thyroid function test abnormalities and serum autoantibodies in Iranian patients. BMC Dermatol 2005;5:11.

[15] Berker DAR, Messenger AG, Sinclair RD. Disorders of hair. In: Rook's Textbook of Dermatology. Burns T, Breathnach S, Cox N, Griffiths C, eds. 7th ed. Oxford: Blackwell Science, 2004:pp. 1-63.

[16] Gandhi V, Baruah MC, Bhattacharaya SN. Nail changes in alopecia areata: incidence and pattern. Indian J Dermatol Venereol Leprol 2003;69:114-5.

[17] Kasumagic-Halilovic E, Prohic A. Nail changes in alopecia areata: frequency and clinical presentation. J Eur Acad Dermatol Venereol 2009;23:240-1.

[18] Sharma VK, Dawn G, Kumar B. Profile of alopecia areata in Northern India. Int J Dermatol 1996;35:22-7.

[19] Pancar GS, Eyupoglu O. Red cell distribution width and mean platelet volume in patients with pityriasis rosea. J Clin Med Res 2016;8:445-8.

[20] Lippi G, Targher G, Montagnana M, Salvagno GL, Zoppini G, Guidi GC. Relation between red blood cell distribution width and inflammatory biomarkers in a large cohort of unselected outpatients. Arch Pathol Lab Med 2009;133:628-32.

[21] Weiss G, Goodnough LT. Anemia of chronic disease. N Engl J Med 2005;352:1011-23.

[22] Kim DS, Shin D, Jee H, Kim TG, Kim SH, Kim DY, et al. Red blood cell distribution width is increased in patients with psoriasis vulgaris: a retrospective study on 261 patients. J Dermatol 2015;42:567-71.

[23] Farkas N, Szabó A, Lóránd V, Sarlós DP, Minier T, Prohászka $\mathrm{Z}$, et al. Clinical usefulness of measuring red blood cell distribution width in patients with systemic sclerosis. Rheumatology (Oxford) 2014;53:1439-45.

[24] Lou Y, Wang M, Mao W. Clinical usefulness of measuring red blood cell distribution width in patients with hepatitis B. PLoS One 2012; 7:e37644. 